\title{
RANCANG BANGUN PALANG PINTU KERETA API OTOMATIS MENGGUNAKAN SENSOR GETAR BERBASIS PLC DAN WIRELESS $X B e e$ Pro S2C
}

\author{
Edy Sumarno \\ Prodi Teknik Elektro UNPAM \\ Jln. Puspitek Raya No 11 Buaran, Tangerang Selatan 15310 INDONESIA \\ e-mail:abiefirman@yahoo.com
}

\begin{abstract}
ABSTRAK
Kereta api merupakan alat transportasi yang banyak diminati oleh masyarakat namun ada sisi lain dari kekurangan kereta api yaitu disepanjang jalur khusus rel kereta api banyak yang tidak difasilitasi dengan adanya palang pintu perlintasan. Maka sering terjadi kecelakaan dijalur perlintasan kereta api salah satunya karena kelalaian operator palang pintu kereta api. Dengan adanya hal ini untuk mengurangi kecelakaan dan mempertambah adanya fasilitas pintu perlintasan kereta api yang tidak ada, maka dibuatlah Rancang Bangun Palang Pintu Kereta Api Otomatis dengan menggunakan Sensor Getar sebagai pendeteksi adanya getaran pada rel kereta api, pintu perlintasan sepenuhnya dikendalikan oleh PLC dan $X B e e$ modul sebagai sistem Wireless agar dapat mengurangi adanya kebutuhan pada kabel. Dengan mendeteksi kedatangan kereta tersebut Sensor Getar dapat bekerja dengan cara memanfaatkan adanya getaran pada rel kereta api, tidak hanya mendeteksi adanya kedatangan kereta, Sensor Getar juga dapat bekerja pendeteksian agar Motor Servo sebagai pintu perlintasan dapat segera tertutup dan terbuka pada miniatur dengan dikendalikan oleh PLC dan Wireless sebagai pemberi triggemya.
\end{abstract}

Kata kunci : sensor getar, XBee Modul, Motor Servo, PLC.

\begin{abstract}
Design Of Automatic Railway Door Use Vibrate Ssensor Based On PLC And Wireless XBee Pro S2C. The train is a means of transportation that is great demand by the public but there is another side of the shortage of trains that's is along special railway tracks that are not facilitated with the doorstop a train. So often there is an accident in the railway crossing one of them due to negligence operator of the doorstop a train. Given this to reduce accidents and increase the presence of railway crossing facilities vibration sensor as a detection of vibration on the railroad, the door is fully controlled by PLC and XBee module as a Wireless system in order to reduce the need for cable. With the arrival of train detects Vibrate Sensors can work by utilizing the presence of a vibrating field on a railroad, not only detects the arrival of the train, a Vibrate Sensor can also work detection so that the Servo Motor as the crossing can be immediately closed and open in miniature with its controlled by $P L C$ and Wireless as the trigger.
\end{abstract}

Keywords: vibrate sensors, XBee Module, Servo Motor, PLC. 


\section{PENDAHULUAN}

Creta api merupakan sarana transportasi yang sangat diminati oleh masyarakat untuk berpergian dari suatu tempat ketempat lainnya. Namun sangat disayangkan terkadang banyak sekali disepanjang jalur perlintasan kereta, terutama jalur perlintasan kereta api antar provinsi banyak yang tidak difasilitasi dengan adanya palang pintu perlintasan kereta api. Karena jalur perlintasan kereta api merupakan salah satu kawasan yang sangat rawan kecelakaan bagi pengguna jalan, baik pejalan kaki maupun pengendara motor roda empat/dua. Saat ini mengoperasian palang pintu perlintasan kereta api masih secara manual digerakkan, banyak hal pengoperasian secara manual sering terjadi kesalahan yang diakibatkan dari keteledoran oleh petugas operator (human error) yang berakibat fatal terhadap keselamatan pengguna jalur perlintasan kereta api.

Seiring berkembangnya zaman baik dari segi teknologi maupun dari segi lainnya, khususnya dibidang transportasi perkereta apian maka diperlukan inovasi yang dapat meningkatkan kemajuan khususnya tingkat keamanan dari kecelakaan. Teknologi tersebut adalah palang pintu perlintasan yang dapat dioperasikan secara otomatis. Dimana komponen utamanya yang akan digunakan pada sistem tersebut adalah PLC dan Sensor Getar.

Palang pintu kereta api otomatis ini memanfaatkan getaran sebagai pendeteksi datangnya kereta api yang lewat dan sinyal tersebut akan dikuatkan olesh sebuah penguat sinyal dengan penerima getaran. Getaran yang diterima akan diolah oleh rangkaian menghasilkan sinyal high (1) atau menghasilkan sinyal low (0) dan kemudian sinyal akan dikirimkan ke XBee modul. Sinyalsinyal yang dikirimkan oleh penguat sinyal inilah yang digunakan untuk mendeteksi keberadaan kereta api yang lewat.

Adapun Tujuan dari Penelitian sebagai berikut:

Tujuan yang dicapai dalam skripsi ini adalah merancang dan membuat Palang Pintu Kereta Api Otomatis berbasis PLC \& Wireless dengan menggunakan PLC OMRON Sysmac CP1E sebagai alat pengendali kerja Motor Servo dan Sensor.

\section{TEORI DASAR}

Programmable Logic Control (PLC) pada dasarnya adalah sebuah computer yang khusus dirancang untuk mengontrol suatu proses atau mesin. Proses yang dikontrol dapat berupa regulasi variabel secara kontinyu seperti pada sistem-sistem servo atau hanya melibatkan kontrol dua keadaan (hidup/mati) saja, tetapi secara berulang-ulang seperti yang sering dijumpai pada mesin pengeboran, sistem conveyor dan lain sebagainya.[4]

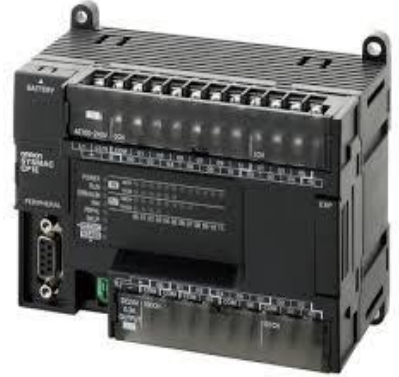

Gambar 1. PLC Omron type CP1E.[5]

Sensor getar adalah suatu alat yang berfungsi untuk mendeteksi adanya getaran dan akan diubah kedalam sinyal listrik. Salah satu jenis getaran yang saat ini sering digunakan adalah accelerometer, alat ini merupakan alat yang dapat 
berfungsi untuk mengukur percepatan dari sebuah benda. Percepatan tersebut diukur bukan dengan menggunakan koordinat dari percepatan tersebut, melainkan dengan mengukur percepatan berdasarkan fenomena pergerakan benda yang dihubungkan dengan perubahan massa yang terjadi didalam alat pengukur tersebut. Contohnya adalah sensor SW-420.[2]

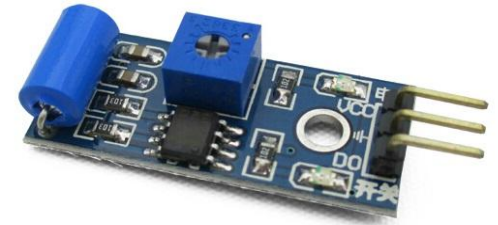

Gambar 2. Sensor Getar type SW-420.

Sensor SW-420 adalah sensor untuk mendeteksi getaran/shock, dimana cara kerja sensor ini adalah dengan menggunakan 1 buah pelampung logam yang akan bergetar didalam tabung yang berisi 2 elektroda ketika modul sensor menerima getaran/shock. Dapat digunakan untuk aplikasi robotika, sensor keamanan, sensor benturan.

Motor servo adalah sebuah perangkat atau aktuator putar (motor) yang dirancang dengan sistem kontrol umpan balik loop tertutup (servo), sehingga dapat di set-up atau diatur untuk menentukan dan memastikan posisi sudut dari poros output motor. Motor servo merupakan motor DC, serangkaian gear, rangkaian kontrol dan potensiometer. Serangakaian gear yang melekat pada poros motor DC akan memperlambat putaran poros dan meningkatkan torsi motor, sedangkan potensiometer dengan perubahan resistansinya saat motor berputar berfungsi sebagai penentu batas posisi putaran poros motor servo. Penggunaan sistem kontrol loop tertutup pada motor servo berguna untuk mengontrol gerakan dan posisi akhir dari poros motor servo. Motor servo biasa digunakan dalam aplikasi-aplikasi di industri, selain itu juga digunakan dalam berbagai aplikasi lain seperti robot, pesawat dan lain sebagainya.[1]

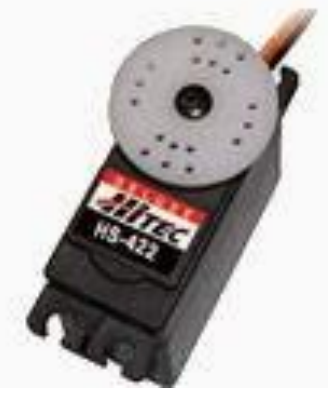

Gambar 3. Motor servo

\section{XBee Pro Module}

Telemetri atau komunikasi data tanpa kabel (wireless) merupakan cara yang efektif untuk komunikasi jarak jauh tanpa harus terganggu dengan jalur kabel yang Panjang. Modul telemetri pun beragam, ada yang menggunakan komunikasi serial yaouti salah satunya $X B$ ee Pro. XBee Pro merupakan modul yang beroperasi pada frekuensi $2.4 \mathrm{GHz}$. Sesuai data sheet, pada saat pengiriman data module XBee Pro memerlukan catu daya 2.8 VDC sampai dengan 3.3 VDC. Modul XBee Pro akan membebani dengan arus $250 \mathrm{~mA}$ pada pengiriman data (Tx) dan arus $50 \mathrm{~mA}$ pada setiap pengiriman data $(\mathrm{Rx})$ dengan jangkauan : 100 meter (indoor), 1500 meter (outdoor). Pada modul XBee Pro terdapat 20 pin, namun yang digunakan hanya 6 pin, yaitu Vcc dan GND untuk tegangan suplai modul, RESET merupakan pin reset XBee Pro, DOUT merupakan pin transmitter (Tx), DIN merupakan pin Receiver $(\mathrm{Rx})$ dan yang terakhir adalah PWMO/RSSI yaotu sebagai indicator 
penerimaan data yang biasa

dihubungkan ke led.[3]

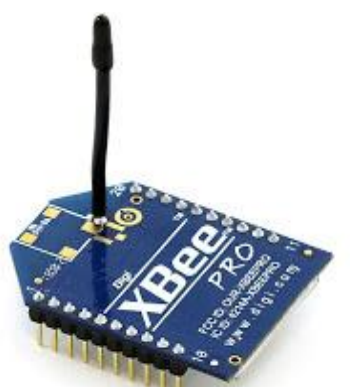

Gambar 4. XBee Pro Modul. 


\section{METODOLOGI PENELITIAN}

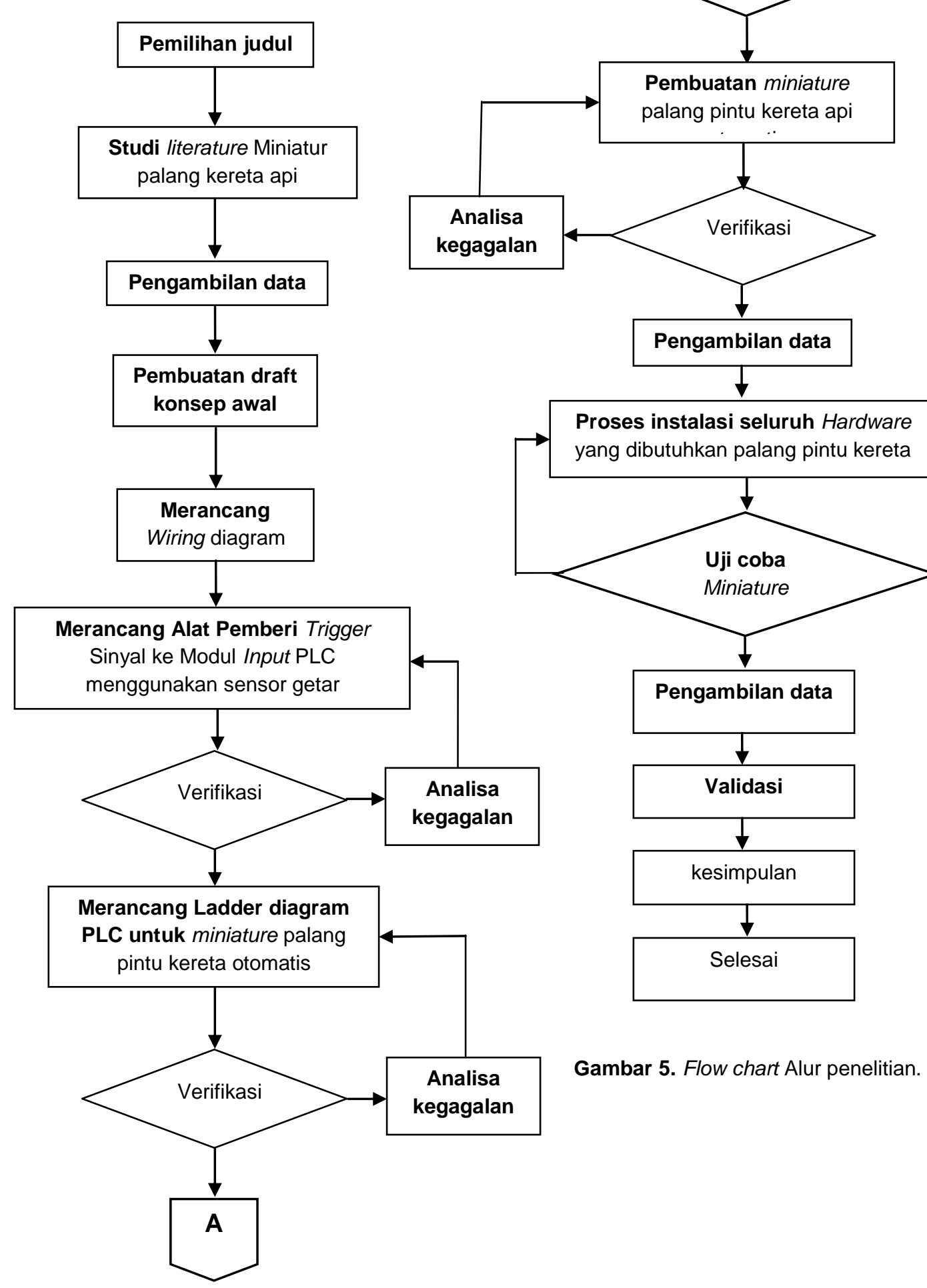




\section{Pembuatan Draft Konsep Awal.}

Dalam konsep awal ini juga akan dibuat blok diagram dari sistem kerja alat palang pintu kereta api otomatis agar dapat mengetahui secara keseluruhan cara kerja dari alat tersebut. Alat yang akan dibuat akan mampu mensimulasikan proses terjadi palang pintu perlintasan kereta secara otomatis dan mampu mengelompokan miniature alat kedalam 4 jenis senso yang berbasis wireless, Gambar blok diagram sistem kontol dapat dilihat pada gambar dibawah ini.

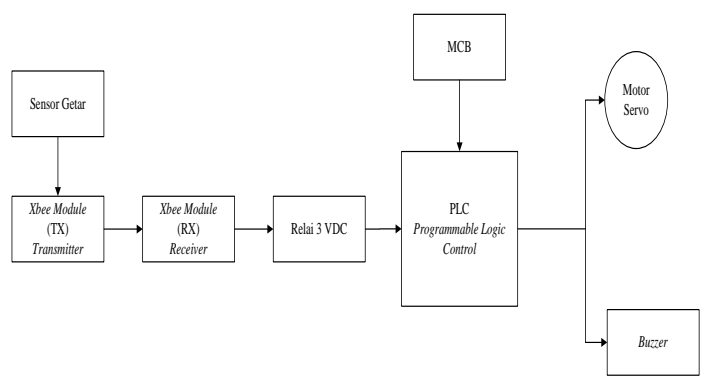

Gambar 6. Blok Diagram Cara kerja miniatur.

\section{Merancang Alat pemberi Trigger sinyal sensor getar kepada XBee Modul.}

Perancangan akan dilakukan dengan data dari sumber-sumber terkait cara kerja sensor getar dan XBee modul, sehingga output dari sensor getar dapat diubah menjadi sinyak yang mampu men-trigger input PLC (Programmable Logic Control). XBee modul (Transmitter) dipergunakan untuk mengolah data berupa wireless yang telah dikirimkan oleh output sensor getar lalu data tersebut akan diterima oleh XBee modul (Reicever) sehingga dapat memberikan output ke relai $3 \mathrm{~V}$ sesuai jarak sensor getar yang telah ditentukan.

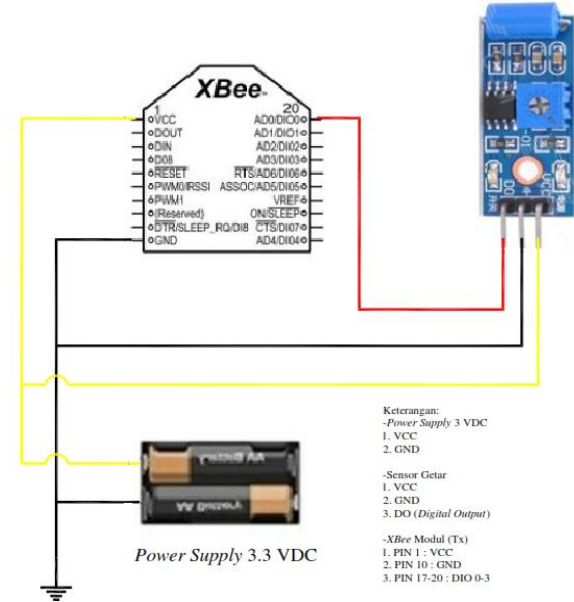

Gambar 7. Wiring Diagram Sensor Getar ke XBee Modul (Tx).

\section{Perangkat Penghubung Antara XBee Modul (Receiver) dengan PLC}

Dalam perancangan dan pembuatan Alat ini sensor getar tidak dapat langsung mengendalikan sistem relai $3 \mathrm{~V}$ dimana data dari sensor getar yang sudah diterima oleh $X B e e$ modul (transmitter) tidak dapat langsung terkirim ke relai $3 \mathrm{~V}$, namun tegangan yang dihasilkan pada XBee Receiver tidak dapat langsung mentrigger pada relai 3V sehingga dibutuhkan rangkaian tambahan yaitu rangkaian switching transistor agar relai $3 \mathrm{~V}$ tersebut dapat bekerja dengan baik.

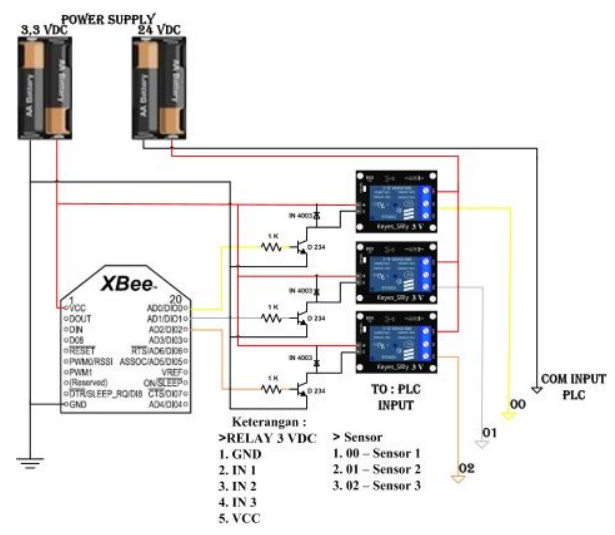

Gambar 8. Wiring Diagram XBee Modul (Receiver) dan Relai 3V. 


\section{Pemrograman XBee Modul}

Membuat pemrograman XBee modul dimana program ini akan mengirim dan menerima data berupa sinyal wireless, pemrograman ini nantinya akan dibuat dan dianalisa berdasarkan getaran yang terdeteksi oleh sensor getar, dengan demikian sinyal sensor getar diterima oleh $X B e e$ modul (receiver) akan terprogram sesuai pin chanel relai yang akan difungsikan sesuai dengan jarak pada sensor getar yang telah ditentukan.

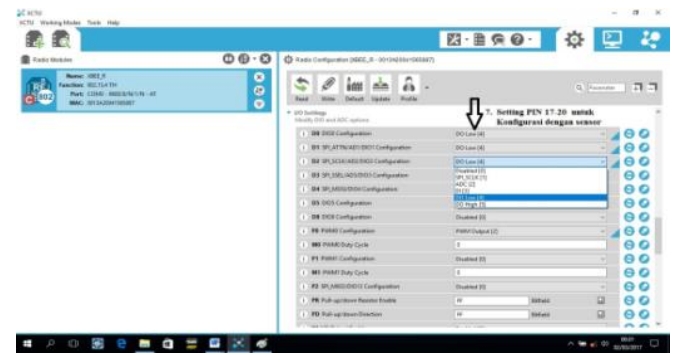

Gambar 9. Program XBee Modul.

\section{Merancang Ladder Diagram PLC}

Dalam penelitian ini dilakukan Perancangan dan Pembuatan Ladder Diagram PLC menggunakan aplikasi PLC Omron yaitu CX-Programer 9.5, PLC bekerja dan menjalankan komponen-komponen sesuai sinyalsinyal input yang sudah didapat dan akan diolah menjadi output.

Berikut adalah salah satu dari ladder diagram dari Palang pintu kereta api otomatis:

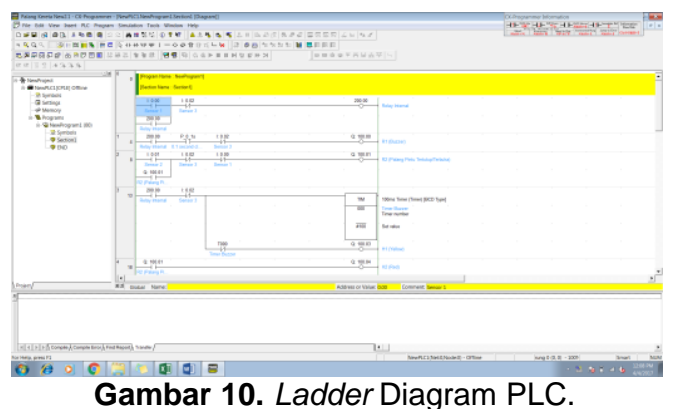

\section{Pembuatan Alat.}

Setelah konsep utama Palang pintu perlintasan kereta api telah diketahui dan Studi Literatur untuk tahapan diatas telah dilaksanakan dan sudah mendapatkan hasil yang sudah baik, maka proses selanjutnya yang akan dilakukan adalah membuat Palang pintu perlintasan kereta api dengan 2 motor servo yang akan menjadi sebagai pintu perlintasan.

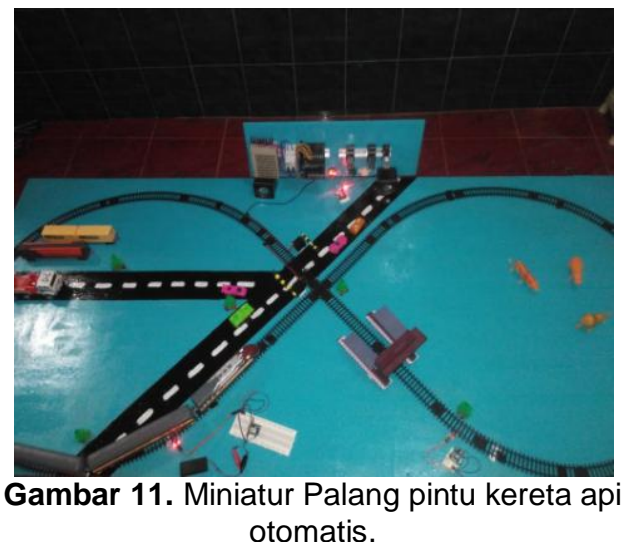

\section{IV.PENGUJIAN DAN ANALISA}

\section{Pengujian Input dan Output dari papan Trainer.}

Pengujian dilakukan untuk memastikan bahwa input dan output dari papan trainer berjalan dengan baik sehingga miniatur dapat bekerja dengan benar, dalam pengujian ini akan diuji akurasi dari sensor apakah dapat bekerja dengan baik atau tidak.

Tabel 1. Peralatan Input (Hardware).

\begin{tabular}{|c|c|c|}
\hline Alamat & Item & Hasil \\
\hline 000 & Relai 1 (PIN 20 XBee dari sensor getar 1) & 0k \\
\hline 001 & Relai 2 (PIN 19 XBee dari sensor getar 2) & Ok \\
\hline 002 & Relai 3 (PIN 18 XBee dari sensor getar 3) & 0k \\
\hline
\end{tabular}


Tabel 2. Peralatan Output (Hardware).

\begin{tabular}{|c|l|c|}
\hline Alamat & \multicolumn{1}{|c|}{ Item } & Hasil \\
\hline 100.00 & Buzzer On & Ok \\
\hline 100.01 & Motor Servo 1 (Pintu Perlintasan Tertutup/Terbuka) & Ok \\
\hline 100.03 & Lampu Indikator Yellow (Buzzer On) & $0 \mathrm{k}$ \\
\hline 100.04 & Lampu Indikator Red (Palang Pintu Tertutup) & Ok \\
\hline 100.05 & Lampu Indikator Green (Palang Pintu Terbuka) & Ok \\
\hline
\end{tabular}

\section{Pengujian Dan Analisa dan XBee Transmitter.}

Pengujian dan analisa ini dilakukan untuk mengetahui apakah sensor dan transmitter pada jarak yang tidak ditetapkan ini dapat bekerja atau tidak, sehingga dapat diketahui apa yang terjadi jika sensor berada dalam jarak yang sudah ditentukan. Pengujian dilakukan diarea terbuka dan tidak melakukan diarea perlintasan kereta api sesungguhnya.

Tabel 3. Pengukuran Modul XBee Transmitter.

\begin{tabular}{|c|c|c|c|c|}
\hline No. & $\begin{array}{c}\text { Jarak } \\
\text { (Meter) }\end{array}$ & $\begin{array}{c}\text { Voltage XBee Tx } \\
\text { (V) VDC }\end{array}$ & $\begin{array}{c}\text { Voltage XBee } \mathrm{Rx} \\
\text { (V) VDC }\end{array}$ & Hasil \\
\hline 1 & 300 & 3,01 & 2,22 & Terkoneksi \\
\hline 2 & 500 & 2,81 & 2,02 & Terkoneksi \\
\hline 3 & 900 & 2,71 & 0,31 & Tidak \\
\hline 4 & 1200 & 2,61 & 0,06 & Tidak \\
\hline 5 & 1500 & 2,55 & 0,02 & Tidak \\
\hline
\end{tabular}

\section{Pengujian Trigger Relai 3V DC Yang} Telah Mendeteksi Pada XBee Receiver.

Proses Pengujian trigger adalah proses yang kedua, proses untuk memberikan sinyal utama dari $X B e e$ receiver ke relai $3 \mathrm{~V}$ DC. Namun sebelum ditrigger pada relai 3V DC dari $X$ Bee receiver, ada rangkaian tambahan yaitu transistor switching berfungsi untuk trigger antara XBee receiver dan relai $3 \mathrm{~V} D C$ agar relai $3 \mathrm{~V}$ DC dapat bekerja dengan baik.

Untuk melakukan pengujian trigger relai pada $X$ Bee receiver maka dilakukan pengujian dengan cara simulasi pada miniature yang ada, berikut adalah data pengukuran pada $X B e e$ receiver dan relai $3 \mathrm{~V}$ DC dalam simulasi pada miniatur tersebut.

Tabel 4. Pengukuran XBee Receiver dan Relai 3V DC.

\begin{tabular}{|c|c|c|c|c|}
\hline No. & ITEM & $\begin{array}{c}\text { Tegangan XBee } \\
\text { Receiver (VDC) }\end{array}$ & $\begin{array}{c}\text { Tegangan Relai 3V } \\
\text { (VDC) }\end{array}$ & Inputan PIC \\
\hline 1 & Sensor 1/ XBee Tx 1 & $2,81 \mathrm{VDC}$ & $2,7 \mathrm{VDC}$ & $23,8 \mathrm{VDC}$ \\
\hline 2 & Sensor 2/ XBee Tx 2 & $2,79 \mathrm{VDC}$ & $2,70 \mathrm{VDC}$ & $23,6 \mathrm{VDC}$ \\
\hline 3 & Sensor 3/ XBee Tx 3 & $2,80 \mathrm{VDC}$ & $2,7 \mathrm{VDC}$ & $23,8 \mathrm{VDC}$ \\
\hline
\end{tabular}

\section{Pengujian I/O Pada Miniatur Palang Pintu Kereta Api Dengan Cara Otomatis.}

Setelah proses pengujian papan trainer dan pengujian trigger dari XBee Receiver bekerja dengan baik maka tahap selanjutnya adalah pengujian ladder diagram sensor getar yang sebelumnya telah di trigger menuju $X B e e$ receiver dan pengujian Motor Servo beserta buzzer yang terdapat pada miniatur palang pintu kereta api otomatis dimana pada proses ini palang pintu dan modul buzzer dalam keadaan hidup atau bekerja jika pada inputan PLC telah mendapatkan sinyal dari $X B e e$ receiver.

Pada proses sebelumnya telah dijelaskan cara dan hasil dari proses utama sampai data analisa dan pengukuran sehingga dalam pengujian ladder diagram ini tidak dibahas, proses ini akan membahas alat yang sudah terdeteksi pada sensor akan membuka dan menutup palng pintu kereta api serta menghidupkan buzzer dan lampu indikator akan menyala sesuai dengan masing-masing yang telah dibuat dalam ladder diagram tersebut. 


\section{Hasil Dari Seluruh Pengujian Ladder Diagram PLC.}

Dari semua pengujian diatas telah didapatkan kesimpulan bahwa semua program berjalan dengan baik sehing input yang didapat oleh PLC dapat menjadi output yang benar sesuai dengan apa yang diinginkan. Berikut adalah table dari kesimpulan keseluruhan input yang bekerja dan menghasilkan output yang berbeda:

Tabel 5. Pengujian keseluruhan program dari Ladder diagram.

\begin{tabular}{|c|c|c|c|c|c|}
\hline Input & Data & Output & Data & Hasil & Keterangan \\
\hline Sensor 1 & 00.00 & Buzzer & 100.00 & $100 \%$ & $0 \mathrm{k}$ \\
\hline & & Indikator Lampu Yellow & 100.03 & $100 \%$ & $0 \mathrm{k}$ \\
\hline Sensor 2 & 00.01 & Palang Pintu Tertutup & 100.01 & $100 \%$ & $0 \mathrm{k}$ \\
\hline & & Indikator Lampu Red & 100.04 & $100 \%$ & $0 \mathrm{k}$ \\
\hline Sensor 3 & 00.02 & Palang Pintu Terbuka & 100.01 & $100 \%$ & $0 \mathrm{k}$ \\
\hline & & Indikator Lampu Green & 100.05 & $100 \%$ & $0 \mathrm{k}$ \\
\hline
\end{tabular}

\section{KESIMPULAN}

Miniatur palang pintu kereta api otomatis telah dapat bekerja berdasarkan 3 sensor getar dan XBee Transmitter dengan jarak yang berbeda dan XBee Receiver sebagai penerima untuk mentrigger dari Sensor ke PLC Sebagai pengendali Motor Servo.

Pada wireless dapat bekerja secara baik dan saling terkoneksi antara XBee Transmitter dan XBee Receiver, namun wireless tersebut hanya dapat terkoneksi dengan jarak maksimal 0-500 Meter.

Masing-masing jarak sensor dan XBee transrmitter $1,2, \& 3$ dengan XBee receiver maupun PLC telah ditentukan dengan jarak yang berbeda-beda dalam penempatannya yaitu : a) Sensor \& XBee Transmitter 1: 1500 Meter dari XBee Receiver \& PLC

b) Sensor \& XBee Transmitter 2: 1000 Meter dari XBee Receiver \& PLC.

c) Sensor \& XBee Transmitter 3 : 400 Meter dari XBee Receiver \& PLC.

Untuk tegangan yang dihasilkan oleh $X B e e$ receiver modul hanya sebesar 3VDC maka perlu modul tambahan untuk menaikan atau menstabilkan tegangan agar tegangan yang dihasilkan dapat mentrigger dengan relai atau SSR (Solid State Relay).

\section{VI.DAFTAR PUSTAKA}

[1] Prawitasari, Nila. 2013. Pengertian Motor Servo.

[2] Bishop, Owen. 2004. Dasar-dasar Elektronika. Jakarta: Erlangga.

[3] International, Digi Inc. 2009. XBee/XBee Pro RF Module Datasheet Minnetonka.

[4] Handy Wicaksono. Programmable Logic Controller Teori, Pemrograman dan Aplikasinya dalam Otomasi Sistem. Graha Ilmu, Jogjakarta 2009 .

[5] Omron Automation. "CP1E Intructions Reference Manual". Omron, Japan, 2009. 